\title{
ESTUDO ANATÔMICO DO XILEMA SECUNDÁRIO DE Ephedra tweediana C. A. Meyer
}

\author{
José Newton Cardoso Marchiori \\ Universidade Federal de Santa Maria - Santa Maria, RS \\ Graciela I. Bolzon de Muñiz \\ Universidade Federal do Paraná - Curitiba, PR
}

RESUMO

São descritos os caracteres anatômicos do xilema secundário de Ephedra tweediana C.A. Meyer, fornecidas fotomicrografias e dados quantitativos de sua estrutura. Os detalhes observados correspondem ao descrito na literatura para outras espécies do gênero.

A anatomia da madeira destaca-se pela presença de vasos verdadeiros e raios muito altos, com até 8 células de largura. Tais aspectos são comuns em angiospermas dicotiledôneas mas ausentes em gimnospermas, com exceção dos 3 gêneros das Chlamydospermae ou Gnetales. Dentro deste grupo, Ephedra distingue-se por ter placas de perfuração foraminada ou efedróide. Para a espécie sul-brasileira salientam-se ainda a presença de traqueídeos muito curtos, pontoações areoladas em arranjo unisseriado e o contorno peculiar dos anéis de crescimento "em degraus". Palavras-Chave : Anatomia da Madeira, Ephedra tweediana, Chlamydospermae, Gnetales.

\section{SUMMARY}

The anatomical features of the secondary xylem of Ephedra tweediana C.A. Meyer are described. They are also furnished photomicrographs as well as quantitative data of its structure. The wood anatomy fits with the described in the literature to other species of the same genus.

In the wood of Ephedra tweediana they are found real vessels and very tall rays, up to 8 cells wide. These features are common in the Angiosperm Dicotyledons but absent in the Gymnosperms, with the exception of the Chlamydospermae or Gnetales. Ephedra separates itself in this group by the presence of foraminate or "ephedroid" perforation plates. In the xylem anatomy of this south brazilian species, they must be also emphasized the presence of very short tracheids, provided with uniseriate bordered pits and the peculiar "stepped outline" of annual rings.

Keywords : Wood Anatomy, Ephedra tweediana, Chlamydospermae, Gnetales. 


\section{INTRODUÇÃO}

O gênero Ephedra L. reúne cerca de 42 espécies, distribuídas nas zonas áridas subtropical e temperada de ambos os hemisférios. São geralmente plantas arbustivas, menos comumente lianas, providas de folhas escamiformes em arranjo oposto ou verticilado. Os caules são delgados, cilindricos e articulados, com numerosas ramificações. A utilidade potencial das espécies parece residir na produção de efedrina, um alcalóide de largo uso medicinal. LAWRENCE (1977) refere a este respeito, a comercialização de 100 toneladas de produto não purificado de origem asiática, apenas no ano de 1935 .

A espécie em estudo é originária do sul do Brasil, Uruguai e Argentina (CABRERA \& ZARDINI, 1978, LOMBARDO, 1964). Trata-se de um arbusto apoiante, dióico, de até $6 \mathrm{~m}$ de altura e com pequenas folhas caducas (2 - $5 \mathrm{~mm}$ ). Os estróbilos masculinos são globosos (de 4 a 7 $\mathrm{mm}$ ) e os femininos avermelhados e carnosos, medindo de 8 a $10 \mathrm{~mm}$ de comprimento. As sementes são pequenas ( $8 \mathrm{~mm}$ ), ovadas, castanhas e plano-convexas (DIMITRI, 1978).

O presente estudo visa a descrição anatômica do xilema secundário do caule de Ephedra tweediana e a comparação de seus detalhes estruturais com referências da literatura sobre o gênero e familia a que pertence.

\section{REVISÃO DE LITERATURA}

A familia Ephedraceae insere-se na classe Chlamydospermae e ordem Gnetales (SPORNE, 1974; MELCHIOR \& WERDERMANN, 1954), interpretadas pelos taxonomistas como ramos terminais da evolução filogenética ou então como grupos intermediários entre Gymnospermae e Angiospermae.

Dentre os caracteres morfológicos lembrados para justificar a posição intermediária das Chlamydospermae entre as duas últimas divisões do Reino Vegetal, inclui-se a presença nestas plantas de elementos vasculares verdadeiros e raios largos, características ausentes nas coníferas e típicas das folhosas.

As perfurações nos vasos de Ephedra são sempre reticuladas, ocorrendo em um padrão tão peculiar que justifica a denominação de "efedróide", de acordo com GREGUSS (1955). Nos demais gêneros de Chlamydospermae, as placas de perfuração são do tipo simples.

BOUREAU (1960) afirma que estas placas derivam da fusão de aberturas circulares individuais (padrão efedróide), sendo portanto distintas das placas simples encontradas nas 
Angiospermas, que tem como precursoras o padrão escalariforme. De acordo com o mesmo autor, esta diferença ontogenética sugere linhas distintas de evolução para Chlamydospermae e Angiospermae.

GREGUSS (1955) destaca que as pontoações areoladas de Ephedra sp. possuem forma oval e nunca poligonal, dispondo-se em 2-3 séries muito aproximadas. De acordo com o mesmo, este aspecto é distinto do verificado em Welwitschia e Gnetum, demonstrando que os 3 gêneros de Chlamydospermae não possuem uma origem comum.

SAVROV (1956) descreveu as principais características anatômicas de 9 espécies de Ephedra da ex União Soviética. Além do reconhecimento de semelhanças e diferenças estruturais entre as mesmas, o autor chamou a atenção para a presença comum de raios largos e o contorno muito peculiar dos anéis de crescimento "em degraus".

RECORD \& HESS (1949) destacam para espécies americanas a presença de poros numerosos, com diâmetro pequeno a muito pequeno, tipicamente solitários e com distribuição uniforme ou em arranjo mais ou menos zonado no lenho inicial. Os raios foram descritos como sendo muito variáveis em um mesmo espécime e heterogêneos, contendo células abundantemente pontoadas, de tamanho e formas muito variadas. O parênquima axial é muito escasso e difuso. Os traqueídeos são radialmente achatados no lenho tardio e dotados de grandes pontoações areoladas, tanto nas faces radiais como tangenciais da parede celular, aspectos também observados em numerosas coniferas.

Para Ephedra distachya L., GREGUSS (1955) relaciona a presença de raios 3-7-8seriados, semelhantes aos de Casuarina, e de vasos solitários ou em grupos de 3 a 5 . De acordo com o mesmo autor, a ocorrência de vasos, o parênquima paratraqueal e a natureza de suas perfurações são muito peculiares no gênero, distinguindo-o facilmente das demais gimnospermas.

\section{MATERIAL E MÉTODOS}

O material estudado é procedente do municipio de Caçapava do Sul e consiste de 3 amostras de caule, com respectivas exsicatas botânicas, registradas no Herbário do Departamento de Ciências Florestais com os números 3214, 3215 e 3216.

Do material coletado foram preparadas amostras de aproximadamente $1,0 \times 1,0 \times 2$ $\mathrm{cm}$, orientados para a obtenção de cortes anatômicos nos planos transversal, longitudinal radial e longitudinal tangencial. Tais amostras foram amolecidas por fervura em água e seccionadas em micrótomo de deslizamento, regulado para a obtenção de cortes com a espessura nominal de 
$18 \mu \mathrm{m}$.Usou-se tripla coloração, com acridina-vermelha, crisoidina e azul-de-astra (DUJARDIN, 1964), desidratação em série alcoólica, diafanização em xilol e montagem permanente com "Entellan".

Para o preparo de lâminas de macerado foram obtidos finos palitos, mediante fendilhamentos sucessivos do bloco de amostra, retirado da zona mais externa do xilema, com a utilização de um formão bem afiado. Os palitos foram amolecidos por fervura em água, em tubo de ensaio aquecido por banho-maria. Para a maceração usou-se solução de Jeffrey (FREUND, 1970), coloração com safranina e o mesmo meio de montagem anteriormente citado.

As descrições anatômicas seguiram as recomendações da COPANT (1973). Os dados quantitativos são apresentados na Tabela 1 .

As fotomicrografias das Figuras 1, 2 e 3 foram tomadas em aparelho Carl Zeiss, com diferentes aumentos.

\section{DESCRIÇÃO DA MADEIRA}

Vasos : Numerosos $(12,7-19,5-26,7 \mu \mathrm{m})$, ocupando em média $27,6 \%$ da secção transversal da madeira. Poros em distribuição difusa, uniforme; solitários ou em contato parcial com vasos adjacentes. Poros muito pequenos $(28,7-37,6-50 \mu \mathrm{m})$, de secção poligonal e parede relativamente fina.

Elementos vasculares muito longos a extremamente longos (780 - $1.000-1.270 \mu \mathrm{m})$ e providos de placas de perfuração foraminada, em posição quase vertical. Cada placa contém de 6 a 20 perfurações circulares ou ovais, com 11,2 - 14,8 - 17,5 $\mu \mathrm{m}$ de diâmetro, e em arranjo alterno (Figuras 2.B; 3.C-D).

Espessamentos espiralados e apêndices, ausentes.

Pontoações areóladas relativamente escassas e de diâmetro grande $(12,5-14,3-16,3 \mu \mathrm{m})$, normalmente em uma única fileira ou localmente 2-3-seriadas. Possuem forma circular a oval e abertura circular, inclusa.

Pontoações raio-vasculares e parênquimo-vasculares do tipo simples, pequenas e arredondadas.

Parênquima Axial : Ocupando em média $14,8 \%$ do volume da madeira e em arranjo apotraqueal sub-agregado. O contato com vasos é eventual (Figura 1.D). Células de parênquima axial com 195 - 350 - $500 \mu \mathrm{m}$ de altura por 16,2 - 20,5 - $25 \mu \mathrm{m}$ de diâmetro, organizadas em séries de 2, menos comumente 3 células. 

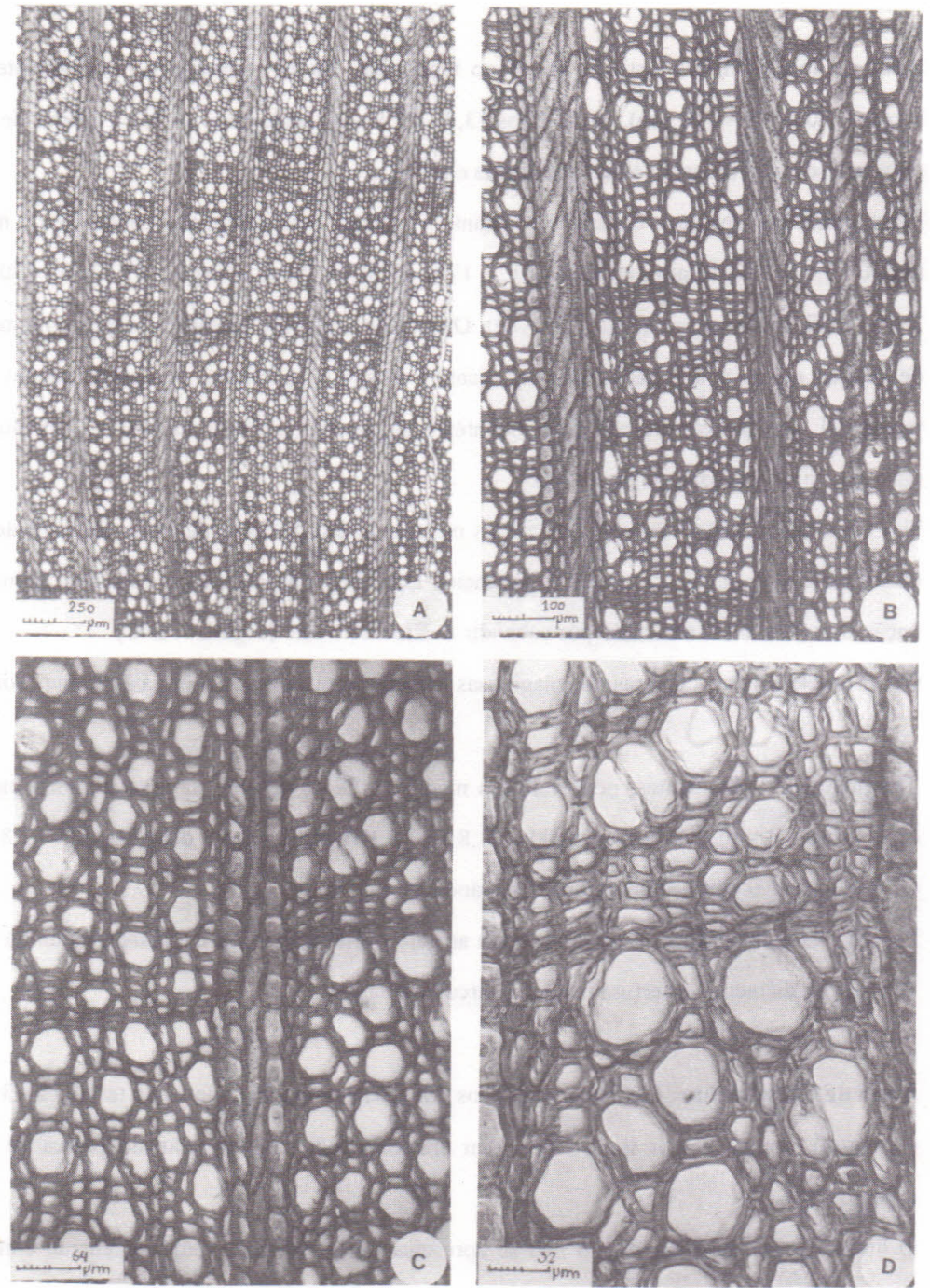

Figura 1. Fotomicrografias de seç̧ões transversais da madeira. A. Porosidade difusa e limitesde anel de crescimento descontínuos, segmentados em degraus pelos raios largos. B. Os mesmos aspectos anatômicos, com maior aumento. C. Detalhe de um raio largo, interrompendo a continuidade do limite do anel. D. Vasos de secção poligonal, células de parênquima axial e traqueídeos.

Raios : Pouco numerosos (3 - 5 - $8 / \mathrm{mm}$ ), mas ocupando em média $27,6 \%$ do volume da madeira.

Tecido radial fracamente heterogêneo, composto de células quadradas, eretas e até curtamente procumbentes (Figura 2.A). Células de parênquima radial de paredes espessas e densamente pontoadas. 
Raios de dois tamanhos distintos em plano tangencial. Raios unisseriados relativamente escassos, baixos (140 - $379-530 \mu \mathrm{m})$, muito finos 13,7 - 21,5 - $30 \mu \mathrm{m}$ ), com 1 - 4 - 7 células de altura. Os raios unisseriados reúnem células quadradas e eretas.

Raios multisseriados com dimensões bastante variáveis, mas sobretudo conspícuos : muito altos $(2.650-3.328-4.930 \mu \mathrm{m})$, com $64-112$ - 172 células de altura, e largos $(87-110-130 \mu \mathrm{m})$, com 2 - 6 - 8 células de largura (Figura 3. A-D). Os grandes raios são também compostos principalmente de células eretas e quadradas mas apresentam zonas com células de menor secção em plano tangencial, que são curtamente procumbentes e de paredes verticais inclinadas, quando vistas em plano longitudinal radial (Figura 2. A).

Nos raios maiores são freqüentes as células mostrando diferentes estágios de crescimento diagonal, quando vistas em plano longitudinal tangencial. Este forma de crescimento confere às mesmas uma feição de célula axial, acabando por subividir finalmente o raio (Figura 3. B-C).

Células esclerosadas, oleiferas, mucilaginosas e latericuliformes, ausentes na estrutura radial.

Traqueídeos : Abundantes, ocupando em média $30 \%$ do volume da madeira. São muito curtos (890 - 1.101- $1.440 \mu \mathrm{m})$, estreitos $(15-21,8-32,5 \mu \mathrm{m})$ e de paredes delgadas $(2,5-3,8-5,0 \mu \mathrm{m})$ Os traqueídeos tem seç̧ão poligonal em plano transversal

Pontoações areoladas intertraqueoidais em arranjo unisseriado. São circulares, medindo 7,5 - 9,8 $12,5 \mu \mathrm{m}$ de diâmetro. Abertura pequena, circular e inclusa.

Anéis de Crescimento : Distintos, marcados por uma estreita faixa de lenho tardio ( 2 - 3 células em espessura), composta por traqueídeos com diâmetro radial muito reduzido (cerca de $12 \mu \mathrm{m}$ de espessura)

O limite do anel de crescimento não se apresenta como um arco tangencialmente contínuo. Ao contrário do verificado nas coníferas e angiospermas dicotiledôneas, mostra-se segmentado em degraus, interrompidos pelos raios largos (Figura 1. A-C).

\section{ANÁLISE DA ESTRUTURA ANATÔMICA}

Os caracteres anatômicos do xilema secundário de Ephedra tweediana coincidem com o descrito por GREGUSS (1955), RECORD \& HESS (1949) e SAVROV (1956), para distintas espécies do gênero. 

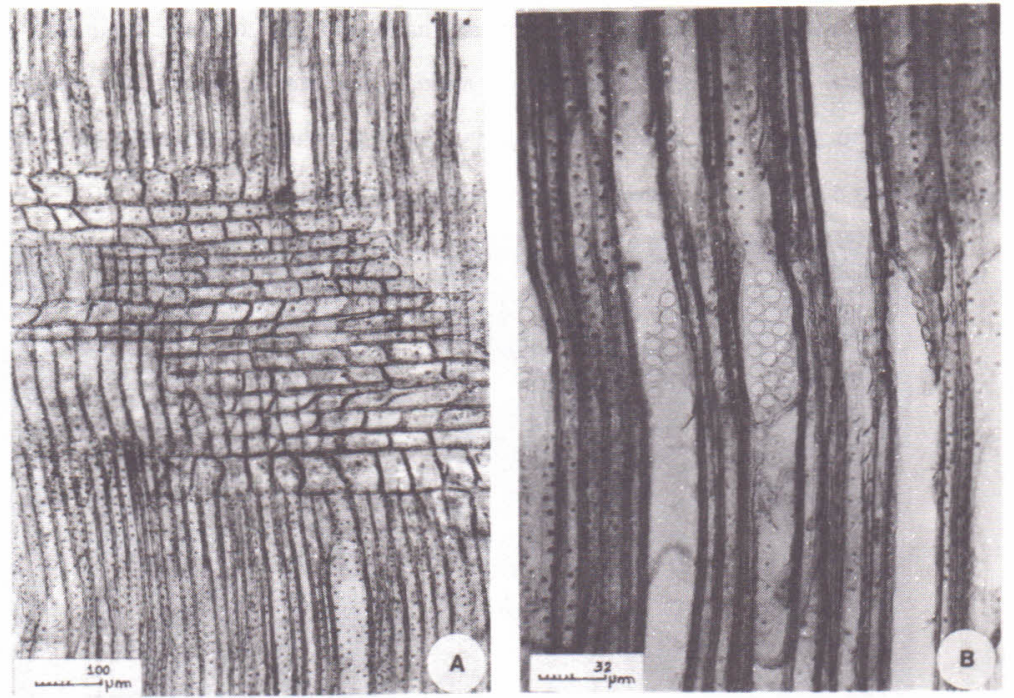

Figura 2. Aspectos anatômicos da secção longitudinal radial. A. Células quadradas, curtamente procumbentes e eretas em raio homocelular. B. Elementos de vaso com placas de perfuração efedróides.

A presença de vasos verdadeiros no xilema distingue prontamente o material em estudo das demais gimnospermas, com exceção dos gêneros Gnetum e Welwitschia, que form?.' juntamente com Ephedra, a classe Chlamydospermae ou ordem Gnetales. Para atribuir o mat ' i i examinado ao gênero Ephedra, basta todavia examinar a natureza das placas de perfuração, compostas por numerosos orificios circulares ou ovais, com diâmetro médio de aproximadamente $15 \mu \mathrm{m}$. Este tipo de placa, dito "foraminado" ou "efedróide", restringe-se ao gênero em estudo, permitindo separar Ephedra das demais plantas lenhosas. Embora ocorram eventualmente placas com mais de uma perfuração circular em Angiospermas, estas nunca são tão numerosas como no material analisado (de 6 a20).

$\mathrm{O}$ diâmetro das perfurações e o arranjo alterno das mesmas na placa, sugerem sua origem através da dissolução da membrana de pontoações. Os valores mínimos, médios e máximos do diâmetro de pontoações e perfurações de vasos são praticamente equivalentes (Tabela 1, características 5 e 7).

Os vasos de Ephedra tweediana possuem diâmetro muito pequeno, à semelhança do verificado nas demais espécies do gênero. Este caráter tem significado ecológico, devendo ser interpretado como xeromórfico e de valor adaptativo à aridez, uma constante nas áreas de distribuição destas plantas.

A condução de seiva no xilema de Ephedra tweediana é também realizada por 
traqueídeos, muito curtos em relação ao verificado na maioria das coniferas. Cabe ainda destacar a forma poligonal e o pequeno diâmetro dos mesmos em secção transversal, aspectos que os assemelham ao parênquima axial. A distinção entre estas células dá-se então pela espessura da parede celular e ausência de conteúdos na cavidade dos traqueideos.
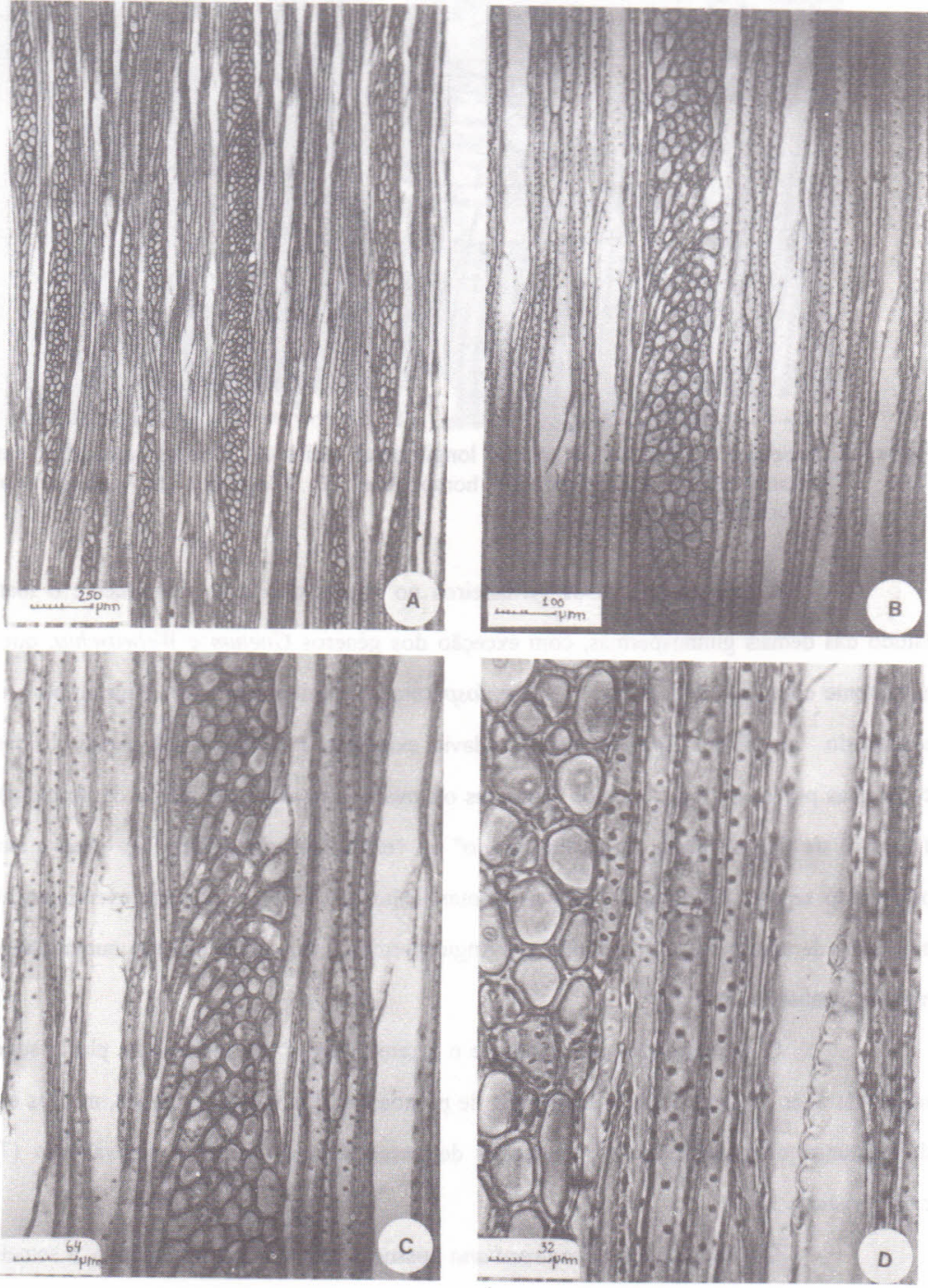

$<$

5

Figura 3. Aspectos anatômicos da secção longitudinal tangencial. A. Raios multisseriados altos, muito altos e vasos. B. Raios unisseriados e multisseriados. C. Células radiais transversalmente alongadas, em fase inicial de segregação de um novo raio; aspecto parcial de uma placa foraminada em vaso. D. Elemento de vaso com placas de perfuração efedróide, traqueídeo longitudinal, parênquima axial seriado e aspecto parcial de um raio multisseriado. 
As pontoações nas paredes longitudinais dos traqueideos assemelham-se ao observado em numerosas coniferas, tendo aréola bem visivel e pequena abertura circular. Encontram-se normalmente bastante espaçadas e em arranjo unisseriado, sendo pouco freqüentes as crássulas e linhas de contato entre as mesmas. Tal aspecto lembra o verificado em certas podocarpáceas e cupressáceas, embora com menores diâmetros do que nestes casos

O parênquima axial em Ephedra tweediana, ao contrário do descrito por RECORD \& HESS (1949) para outras espécies americanas, não pode ser definido como muito escasso ou difuso. Este tipo celular corresponde a cerca de $14,8 \%$ da secção transversal da madeira (Tabela 1, característica 8), e distribui-se de forma apotraqueal, estabelecendo contatos apenas eventuais com vasos, ou formando curtos segmentos tangenciais (arranjo sub-agregado). O parênquima axial apresenta séries com geralmente 2 células, dotadas de pontoações simples.

A estrutura dos raios é bastante peculiar às espécies de Ephedra, contribuindo para a sua identificação. A observação de raios muito altos e com até 8 células de largura, distingue facilmente este gênero de qualquer madeira de conifera. Sua estrutura assemelha-se ao observado em certas dicotiledôneas, como lembra GREGUSS (1955). A predominância de células quadradas, associadas a formas curtamente procumbentes ou eretas, bem como a abundància de pontoações na parede, lembram certas angiospermas dicotiledôneas como ('asuarina sp. e Drimys brasiliensis. As diferenças entre as mesmas são contudo evidentes.

O mecanismo de formação de novos raios, mediante o alongamento diagonal de células parenquimáticas radiais assemelha-se ao descrito por MARCHIORI (1985), para Acanthosyris spinescens (Samtalaceae).

Cabe finalmente destacar a segmentação do contorno dos anéis de crescimento e seu aspecto "em degraus", interrompidos pelos grandes raios. Trata-se de um caráter muito peculiar ao gênero, de acordo com SAVROV (1956), RECORD \& HESS (1949) e GREGUSS (1955)

\section{LITERATURA CITADA}

1. BOtreaU, E. Bois hétéroxylé et évolution. Mém. Soc. Bot. France, $1960: 41-49$

2. CABRERA, A.L. \& ZARDINI, E.M. Manual de la Flora de los alrededores de Buenos Aires.Buenos Aires, ACME S.A.C.I, 1978. 755 p.

3. COPANT - COMISION PANAMERICANA DE NORMAS TECNICAS. Descripcion de las caracteristicas generales, macroscopicas y microscopicas. 30:1-019, novembro, 1973. 
4. DIMITRI, M.J. Enciclopedia Argentina de Agricultura y Jardineria. Buenos Aires, ACME, 1978. Tomo I. $651 \mathrm{p}$

5. DUJARDIN, E.P. Eine neue holz-zellulosenfaerbung. Mikrokosmos, 53: 94, 1964.

6. FREUND, H. Handbuch der Mikroskopie in der Technik. Frankfurt, Umsham Verlag, 1970. $379 \mathrm{p}$.

7. GREGUSS, P. Identification of Living Gymnosperms on the Basis of Xylotomy. Budapest, Akadémiai Kiadó, 1955. 263 p.

8. LAWRENCE, G.H.M. Taxonomia das Plantas Vasculares. Lisboa, Fundação Calouste Gulbenkian, 1977. 854 p.

9. LOMBARDO, A Flora Arborea y Arborescente del Uruguay. Montevideo, Concejo Departamental, 1964. $151 \mathrm{p}$.

10. MARCHIORI, J.N.C. Estudo anatômico da madeira de Acanthosyris spinescens (Mart. et Eichl.) Gris. (Santalaceae). Ciência e Natura, 7: 107-118, 1985

11. MELChIOR, H. \& WERDERMANN, E. A. Engler's Syllabus der Pflanzenfamilien. Berlin, Gebrüder Borntraeger, 1954. Vol. I. 367 p.

12. RECORD, S.J. \& HESS, R.W. Timbers of the New World. New Haven, Yale University Press, 1949. 640 p.

13. SAVROV, L.A. The wood anatomy of the Ephedra species of the U.S. S.R. Bot Z., 41(9): 1324-1331, 1956.

14. SPORNE, K.R. The morphology of Gymnosperms. London, Hutchinson University Library, 1974. $216 \mathrm{p}$. 
TABELA 1. Dados quantitativos e determinações estereológicas da estrutura anatômica da madeira.

\begin{tabular}{lrrrr}
\hline \hline CARACTERÍSTICA & V. min. & MÉDIA & V.máx & Sx \\
\hline 1. Fração de poros $(5)$ & 26 & 27,6 & 30 & 2,07 \\
2. Freqüência de poros (poros $\left./ \mathrm{mm}^{2}\right)$ & 12,7 & 19,5 & 26,7 & 3,84 \\
3. Diâmetro do lume de poros $(\mu \mathrm{m})$ & 28,7 & 37,6 & 50,0 & 4,28 \\
4. Comprimento elementos vasculares $(\mu \mathrm{m})$ & 780,0 & $1.000,8$ & 1270,0 & 1423,44 \\
5. Ø pontoações de vasos $(\mu \mathrm{m})$ & 12,5 & 14,3 & 16,3 & 1,50 \\
6. No perfurações / placa & 6 & 15 & 20 & 3,31 \\
7. Ø perfurações $(\mu \mathrm{m})$ & 11,2 & 14,8 & 17,5 & 1,48 \\
8. Fração parênquima axial $(\%)$ & 11 & 14,8 & 18 & 3,27 \\
9. H. células parênquima axial $(\mu \mathrm{m})$ & 195,0 & 350,0 & 500,0 & 95,66 \\
10. Ø células parênquima axial $(\mu \mathrm{m})$ & 16,2 & 20,5 & 25,0 & 3,40 \\
11. Fração de raios $(\%)$ & 23,0 & 27,6 & 34,0 & 4,50 \\
12. Freqüência de raios $($ raios $/ \mathrm{mm})$ & 3 & 5 & 8 & 1,48 \\
14. H. raios unisseriados $($ células) & 140 & 379,6 & 530,0 & 131,38 \\
15. L. raios unisseriados $(\mu \mathrm{m})$ & 13,7 & 21,5 & 30,0 & 3,94 \\
16. H. raios multisseriados $(\mu \mathrm{m})$ & $2.650,0$ & $3.328,0$ & $4.930,0$ & 802,02 \\
17. H. raios multisseriados $($ células) & 64 & 112 & 172 & 38,04 \\
18. L. raios multisseriados $(\mu \mathrm{m})$ & 87,0 & 110,3 & 130,0 & 15,58 \\
19. L. raios multisseriados $($ células) & 2 & 6 & 8 & 1,32 \\
20. Fração de traqueideos $(\%)$ & 28 & 30 & 33 & 1,87 \\
21. Comprimento de traqueideos $(\mu \mathrm{m})$ & 890,0 & $1.101,0$ & $1.440,0$ & 153,06 \\
22. Ø de traqueideos $(\mu \mathrm{m})$ & 15,0 & 21,8 & 32,5 & 4,90 \\
23. E. parede de traqueídeos $(\mu \mathrm{m})$ & 2,5 & 3,8 & 5,0 & 0,89 \\
24. Ø pontoações de traqueídeos $(\mu \mathrm{m})$ & 7,5 & 9,8 & 12,5 & 1,27 \\
\hline
\end{tabular}

Ø : Diâmetro; L. : largura; H.: altura; V. mín.: valor mínimo; V. máx. : valor máximo; sx: desvio padrão; E.: espessura 
